\title{
Allee effect increasing the final density of the species subject to the Allee effect in a Lotka-Volterra commensal symbiosis model
}

Qifa Lin ${ }^{1 *}$

"Correspondence:

lqfnd_118@163.com

${ }^{1}$ Department of Mathematics,

Ningde Normal University, Ningde,

P.R. China

\section{Springer}

\begin{abstract}
A Lotka-Volterra commensal symbiosis model with first species subject to the Allee effect is proposed and studied in this paper. Local and global stability property of the equilibria are investigated. An amazing finding is that with increasing Allee effect, the final density of the species subject to the Allee effect is also increased. Such a phenomenon is different from the known results, and it is the first time to be observed. Numeric simulations are carried out to show the feasibility of the main results.
\end{abstract}

MSC: 34C25; 92D25; 34D20; 34D40

Keywords: Lotka-Volterra commensal symbiosis model; Allee effect; Global stability

\section{Introduction}

The aim of this paper is to investigate the dynamic behaviors of the following two species commensal symbiosis model incorporating the Allee effect to the first species:

$$
\begin{aligned}
& \frac{d x}{d t}=x\left(b_{1}-a_{11} x\right) \frac{x}{\beta+x}+a_{12} x y, \\
& \frac{d y}{d t}=y\left(b_{2}-a_{22} y\right),
\end{aligned}
$$

where $b_{i}, a_{i i}, i=1,2, \beta$ and $a_{12}$ are all positive constants, $b_{i}, i=1,2$, is the intrinsic growth rate of the species $x$ and $y$, respectively; $\frac{b_{i}}{a_{i j}}, i=1,2$, is the carrying capacity of species $x$ and $y$, respectively; $a_{12}$ reflects the efficiency of every single population $y$ that can contribute to population $x$. We use the term $F(x)=\frac{x}{\beta+x}$ to describe the Allee effect of the first species, which has the following property:

(1) $F^{\prime}(x)=\frac{\beta}{(\beta+x)^{2}}>0$ for all $x \in(0,+\infty)$, that is, the Allee effect decreases as density increases;

(2) $\lim _{x \rightarrow+\infty} F(x)=1$, that is, the Allee effect vanishes at high densities.

During the last decades, many scholars investigated the dynamic behaviors of the mutualism model or commensalism model [1-26]. Such topics as the stability of the positive equilibrium $[1-3,8-12,14-17,19,20,24]$, the persistence of the system $[4,6,7,13]$, the existence of the positive periodic solution [18,21, 22, 25], the extinction of the species

(c) The Author(s) 2018. This article is distributed under the terms of the Creative Commons Attribution 4.0 International License (http://creativecommons.org/licenses/by/4.0/), which permits unrestricted use, distribution, and reproduction in any medium, provided you give appropriate credit to the original author(s) and the source, provide a link to the Creative Commons license, and indicate if changes were made. 
$[5,23]$ etc. have been extensively investigated. Recently, Han and Chen [20] proposed the following commensalism model:

$$
\begin{aligned}
& \frac{d x}{d t}=x\left(b_{1}-a_{11} x\right)+a_{12} x y, \\
& \frac{d y}{d t}=y\left(b_{2}-a_{22} y\right) .
\end{aligned}
$$

System (1.2) admits a positive equilibrium $P_{0}\left(x_{0}, y_{0}\right)$, where

$$
\begin{aligned}
& x_{0}=\frac{b_{1} a_{22}+b_{2} a_{12}}{a_{11} a_{22}}, \\
& y_{0}=\frac{b_{2}}{a_{22}} .
\end{aligned}
$$

Concerned with the stability property of this equilibrium, the authors obtained the following result.

Theorem A The positive equilibrium $P_{0}\left(x_{0}, y_{0}\right)$ of system (1.2) is globally stable.

On the other hand, the Allee effect, which represents a negative density dependence where the population growth rate reduces at low population size, has recently been studied by many scholars (see [26-37] and the references cited therein). Specially, Hüseyin Merdan [36] proposed the following predator-prey system with Allee effect on prey species:

$$
\begin{aligned}
& \frac{d x}{d t}=r x(1-x) \frac{x}{\beta+x}-a x y, \\
& \frac{d y}{d t}=a y(x-y),
\end{aligned}
$$

where $\beta$ is a positive constant, which describes the intensity of the Allee effect. Hüseyin Merdan showed that the system subject to an Allee effect takes a longer time to reach its steady-state solution, and the Allee effect reduces the population densities of both predator and prey at the steady-state.

Recently, Wu et al. [37] proposed the following two species commensal symbiosis model with Holling type functional response and Allee effect on the second species:

$$
\begin{aligned}
& \frac{d x}{d t}=x\left(a_{1}-b_{1} x+\frac{c_{1} y^{p}}{1+y^{p}}\right), \\
& \frac{d y}{d t}=y\left(a_{2}-b_{2} y\right) \frac{y}{\beta+y},
\end{aligned}
$$

where $a_{i}, b_{i}, i=1,2, p, \beta$, and $c_{1}$ are all positive constants, $p \geq 1$. They showed that the Allee effect has no influence on the final density of the species, and the unique positive equilibrium of system (1.5) is globally stable.

It came to our attention that the Allee effect has different influence on systems (1.4) and (1.5). The Allee effect reduces the density of the species in system (1.4), while it has no influence on the final density of the species in system (1.5). Maybe the reason is that the authors made different assumptions: in system (1.4), the authors assumed that the first 
species (prey species) admits the Allee effect, while in system (1.5), the authors assumed that the second species is subjected to the Allee effect. One of the interesting issues proposed is as follows: Noting that [37] studied the influence of the Allee effect on the commensalism model, it is natural to ask: what would happen if we assumed the first species suffers to the Allee effect in a commensalism model? This leads us to proposing system (1.1).

We arrange the paper as follows. In the next section, we investigate the existence and local stability property of the equilibria of system (1.1). In Sect. 3, the Dulac criterion is applied to investigate the global stability property of positive equilibrium of system (1.1). In Sect. 4, an example together with its numeric simulations is presented to show the feasibility of the main results. We end this paper with a brief discussion.

\section{Local stability}

We now analyze the stability of steady-state solutions of system (1.1), subject to an Allee effect on the first population. Defining

$$
f(x, y):=x\left(b_{1}-a_{11} x\right) \frac{x}{\beta+x}+a_{12} x y \text { and } g(x, y):=y\left(b_{2}-a_{22} y\right),
$$

the steady-state solutions of (1.1) are obtained by solving the equations $f(x, y)=0$ and $g(x, y)=0$. Obviously, the model has four steady-state solutions: $A_{1}(0,0), B_{1}\left(\frac{b_{1}}{a_{11}}, 0\right)$, $C_{1}\left(0, \frac{b_{2}}{a_{22}}\right)$, and $D_{1}\left(x^{*}, y^{*}\right)$, where

$$
\begin{aligned}
& x^{*}=\frac{1}{2} \frac{a_{12} b_{2}+a_{22} b_{1}+\sqrt{4 a_{11} a_{22} a_{12} b_{2} \beta+\left(a_{12} b_{2}+a_{22} b_{1}\right)^{2}}}{a_{11} a_{22}}, \\
& y^{*}=\frac{b_{2}}{a_{22}} .
\end{aligned}
$$

Concerned with the local stability property of the above four equilibria, we have the following.

Theorem $2.1 D_{1}\left(x^{*} ; y^{*}\right)$ is locally asymptotically stable; $A_{1}(0,0), B_{1}\left(\frac{b_{1}}{a_{11}}, 0\right)$ and $C_{1}\left(0, \frac{b_{2}}{a_{22}}\right)$ are all unstable.

Proof The Jacobian matrix of model (1.1) at an equilibrium $E(x, y)$ is

$$
J(x, y)=\left(\begin{array}{cc}
\Gamma & a_{12} x \\
0 & b_{2}-2 a_{22} y
\end{array}\right),
$$

where

$$
\Gamma=\frac{\left(-2 x a_{11}+b_{1}\right) x}{\beta+x}+\frac{-a_{11} x^{2}+b_{1} x}{\beta+x}-\frac{\left(-a_{11} x^{2}+b_{1} x\right) x}{(\beta+x)^{2}}+a_{12} y .
$$

The local stability of these solutions is discussed below.

For $A_{1}(0,0)$, we have

$$
J\left(A_{1}\right)=\left(\begin{array}{cc}
0 & 0 \\
0 & b_{2}
\end{array}\right) .
$$


Obviously, the two eigenvalues of $J\left(A_{1}\right)$ are $\lambda_{1}=0$ and $\lambda_{2}=b_{2}>0$. Hence, the equilibrium $A_{1}$ is non-hyperbolic. To determine the stability property of this equilibrium, now let us consider the transformation $X=x, Y=y, \tau=b_{2} t$, then system (1.1) becomes

$$
\begin{aligned}
& \frac{d X}{d \tau}=X\left(b_{1}-a_{11} X\right) \frac{X}{b_{2}(\beta+X)}+\frac{a_{12}}{b_{2}} X Y, \\
& \frac{d Y}{d \tau}=Y-\frac{a_{22}}{b_{2}} Y^{2} .
\end{aligned}
$$

Expanding system (2.3) in the power series up to the third order around the origin, we get

$$
\begin{aligned}
& \frac{d X}{d \tau}=P_{2}(X, Y), \\
& \frac{d Y}{d \tau}=Y+Q_{2}(X, Y),
\end{aligned}
$$

where

$$
\begin{aligned}
P_{2}(X, Y)= & \frac{X^{2} b_{1}}{b_{2} \beta}+\frac{a_{12} X Y}{b_{2}}+\frac{X^{3}}{b_{2} \beta}\left(-a_{11}-\frac{b_{1}}{\beta}\right) \\
& +\frac{X^{4}\left(a_{11} \beta+b_{1}\right)}{b_{2} \beta^{3}}-\frac{X^{5}\left(a_{11} \beta+b_{1}\right)}{b_{2} \beta^{4}}+P_{6}(X, Y), \\
Q_{2}(x, y)= & -\frac{a_{22} Y^{2}}{b_{2}} .
\end{aligned}
$$

Here $P_{6}(X, Y)$ is the power series with terms $X^{i} Y^{j}$ satisfying $i+j \geq 6$. Noting that in $P_{2}(X, Y)$ the coefficient of the term $\frac{X^{2} b_{1}}{\beta b_{2}}$ is $\frac{b_{1}}{\beta b_{2}}>0$, by Theorem 7.1 in Chaper 2 of [38], the boundary equilibrium $(0,0)$ of system $(2.4)$ is saddle-node. Consequently, the equilibrium $A_{1}(0,0)$ of system $(1.1)$ is saddle-node, hence, it is unstable.

Now let us consider the equilibrium $B_{1}\left(\frac{b_{1}}{a_{11}}, 0\right)$. The Jacobian matrix of system (1.1) about the equilibrium $B_{1}\left(\frac{b_{1}}{a_{11}}, 0\right)$ is given by

$$
\left(\begin{array}{cc}
-\frac{b_{1}^{2}}{a_{11}}\left(\beta+\frac{b_{1}}{a_{11}}\right)^{-1} & \frac{a_{12} b_{1}}{a_{11}} \\
0 & b_{2}
\end{array}\right) .
$$

(2.6) shows that the two eigenvalues of $J\left(B_{1}\right)$ are $\lambda_{1}=-\frac{b_{1}^{2}}{a_{11}}\left(\beta+\frac{b_{1}}{a_{11}}\right)^{-1}<0$ and $\lambda_{2}=b_{2}>0$. Hence, the equilibrium $B_{1}$ is unstable.

Now let us consider the equilibrium $C_{1}\left(0, \frac{b_{2}}{a_{22}}\right)$, the Jacobian matrix of system (1.1) about the equilibrium $C_{1}\left(0, \frac{b_{2}}{a_{22}}\right)$ is given by

$$
\left(\begin{array}{cc}
\frac{a_{12} b_{2}}{a_{22}} & 0 \\
0 & -b_{2}
\end{array}\right)
$$

(2.7) shows that the two eigenvalues of $J\left(C_{1}\right)$ are $\lambda_{1}=\frac{a_{12} b_{2}}{a_{22}}>0$ and $\lambda_{2}=-b_{2}<0$. Hence, the equilibrium $C_{1}$ is unstable. 
Now let us consider the stability property of the positive equilibrium $D_{1}\left(x^{*}, y^{*}\right)$. Note that $\left(x^{*}, y^{*}\right)$ satisfies the equations

$$
\begin{aligned}
& \left(b_{1}-a_{11} x^{*}\right) \frac{x^{*}}{\beta+x^{*}}+a_{12} y^{*}=0, \\
& b_{2}-a_{22} y^{*}=0 .
\end{aligned}
$$

Hence, from (2.1)

$$
\begin{aligned}
\Gamma\left(x^{*}, y^{*}\right)= & \frac{\left(-2 x^{*} a_{11}+b_{1}\right) x^{*}}{\beta+x^{*}}+\frac{-a_{11} x^{* 2}+b_{1} x^{*}}{\beta+x^{*}} \\
& -\frac{\left(-a_{11} x^{* 2}+b_{1} x^{*}\right) x^{*}}{\left(\beta+x^{*}\right)^{2}}+a_{12} y^{*} \\
= & -a_{12} y^{*}-\frac{a_{11}\left(x^{*}\right)^{2}}{\beta+x^{*}}-a_{12} y^{*} \\
& -\frac{x^{*}}{\beta+x^{*}}\left(-a_{12} y^{*}\right)+a_{12} y^{*} \\
= & a_{12} y^{*}\left(-1+\frac{x^{*}}{\beta+x^{*}}\right)-\frac{a_{11}\left(x^{*}\right)^{2}}{\beta+x^{*}} \\
= & -\frac{\beta a_{12} y^{*}}{\beta+x^{*}}-\frac{a_{11}\left(x^{*}\right)^{2}}{\beta+x^{*}} .
\end{aligned}
$$

By using (2.1), (2.8), and (2.9), the Jacobian matrix of system (1.1) about the equilibrium $D_{1}\left(x^{*}, y^{*}\right)$ is given by

$$
\left(\begin{array}{cc}
-\frac{\beta a_{12} y^{*}}{\beta+x^{*}}-\frac{a_{11}\left(x^{*}\right)^{2}}{\beta+x^{*}} & a_{12} x^{*} \\
0 & -a_{22} y^{*}
\end{array}\right) .
$$

(2.10) shows that the two eigenvalues of $J\left(D_{1}\right)$ are $\lambda_{1}=-\frac{\beta a_{12} y^{*}}{\beta+x^{*}}-\frac{a_{11}\left(x^{*}\right)^{2}}{\beta+x^{*}}<0$ and $\lambda_{2}=$ $-a_{22} y^{*}<0$. Hence, the equilibrium $D_{1}$ is locally asymptotically stable.

This ends the proof of Theorem 2.1.

\section{Global stability}

Previously, we have shown that three boundary equilibria of system (1.1) are all unstable, and the positive equilibrium is locally asymptotically stable. In this section, we will investigate the global dynamic behaviors of system (1.1). Indeed, we have the following result.

Theorem 3.1 The positive equilibrium $D_{1}\left(x^{*}, y^{*}\right)$ of system (1.1) is globally asymptotically stable.

Proof To end the proof of Theorem 3.1, it is enough to show that system (1.1) has no limit cycle in the first quadrant. Set

$$
P_{1}=x\left(b_{1}-a_{11} x\right) \frac{x}{\beta+x}+a_{12} x y, \quad Q_{1}=y\left(b_{2}-a_{22} y\right)
$$


From Theorem 2.1 we know that system (1.1) admits a unique local stable positive equilibrium $D_{1}\left(x^{*}, y^{*}\right)$. Now let us consider the Dulac function $u_{1}(x, y)=\frac{1}{x^{2} y}$. By simple computation, we have

$$
\begin{aligned}
\frac{\partial\left(u_{1} P_{1}\right)}{\partial x}+\frac{\partial\left(u_{1} Q_{1}\right)}{\partial y} & \frac{1}{x^{2} y}\left(\frac{\left(-2 x a_{11}+b_{1}\right) x}{\beta+x}+\frac{-a_{11} x^{2}+b_{1} x}{\beta+x}\right. \\
& \left.-\frac{\left(-a_{11} x^{2}+b_{1} x\right) x}{(\beta+x)^{2}}+a_{12} y\right) \\
& -2 \frac{1}{x^{3} y}\left(\frac{\left(-a_{11} x^{2}+b_{1} x\right) x}{\beta+x}+a_{12} x y\right) \\
& +\frac{-2 a_{22} y+b_{2}}{x^{2} y}-\frac{-a_{22} y^{2}+b_{2} y}{x^{2} y^{2}} \\
= & -\frac{\Delta(x, y)}{(\beta+x)^{2} x^{2} y} \\
< & 0,
\end{aligned}
$$

where

$$
\Delta(x, y)=a_{11} \beta x^{2}+a_{12} \beta^{2} y+2 a_{12} \beta x y+a_{12} x^{2} y+a_{22} \beta^{2} y+2 a_{22} \beta x y+a_{22} x^{2} y+b_{1} x^{2} .
$$

By the Bendixson-Dulac theorem [27], there is no closed orbit in the area $R_{2}^{+}$. So $D_{1}\left(x^{*}, y^{*}\right)$ is globally asymptotically stable. This completes the proof of Theorem 3.1.

Remark 3.1 Compared with Theorem 3.1 and Theorem A, one could easily see that the Allee effect has no influence on the stability property of the positive equilibrium, that is, for the system with or without Allee effect, the system always admits a unique positive equilibrium, which is globally asymptotically stable.

Remark 3.2 Noting that $D_{1}\left(x^{*}, y^{*}\right)$ is the unique positive equilibrium of system (1.1), which is locally asymptotically stable and globally asymptotically stable, and $x^{*}$ depends on the parameter $\beta$, it means that the Allee effect could have influence on final density of the species. However, it could not lead to the extinction of the species, since the positive equilibrium is always globally attractive. Such a finding is very different to that of the Allee effect to the predator-prey system as shown by Hüseyin Merdan [36], where with increase in the Allee effect, the species may be driven to extinction, and the commensalism model with Allee effect on the second species as shown by Wu et al. [37], where the Allee effect has no influence on the final density of the species.

Also, since

$$
\begin{aligned}
& \frac{d x^{*}(\beta)}{d \beta}=\frac{a_{12} b_{2}}{\sqrt{4 a_{11} a_{22} a_{12} b_{2} \beta+\left(b_{1} a_{22}+b_{2} a_{12}\right)^{2}}}>0, \\
& x^{*}(0)=\frac{b_{1} a_{22}+b_{2} a_{12}}{a_{11} a_{22}}=x_{0},
\end{aligned}
$$


it follows that with increasing Allee effect, the final density of the first species is also increasing. Such a phenomenon is very different to that of the phenomenon observed by Hüseyin Merdan [36] and Wu et al. [37].

\section{Numeric simulations}

Example 4.1 Now let us consider the following example.

$$
\begin{aligned}
& \frac{d x}{d t}=x(1-x) \frac{x}{\beta+x}+x y, \\
& \frac{d y}{d t}=y(2-y) .
\end{aligned}
$$

In this system, corresponding to system (1.1), we take $b_{1}=1, b_{2}=2, a_{11}=1, a_{22}=1, a_{12}=1$. It follows from Theorem 3.1 that, for all $\beta>0$, system (4.1) always admits a unique positive equilibrium which is globally asymptotically stable. Figure 1 presents the dynamic behaviors for the case $\beta=2$. Now let us take $\beta=0,0.5$, and 2 , respectively, together with the initial condition $(x(0), y(0))=(0.5,0.1)$. Figure 2 shows that with increase in the Allee effect (i.e., the increase in $\beta$ ), the density of the first species is also increasing.

Figure 1 Dynamic behaviors of system (4.1) with $\beta=2$, the initial condition $(x(0), y(0))=(6,2),(0.1,0.1)$, $(3,3),(0.2,3),(6,0.1)$ and $(6,3)$, respectively

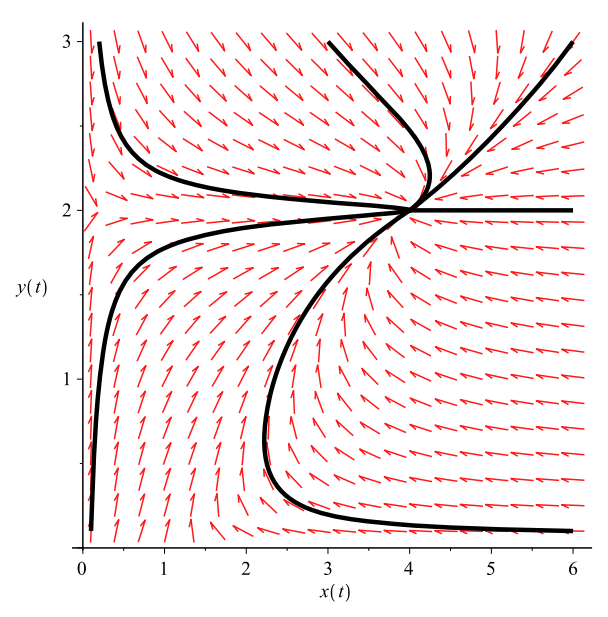

Figure 2 Dynamic behaviors of the first component of system (4.1) with the initial condition $(x(0), y(0))=(0.5,0.1)$

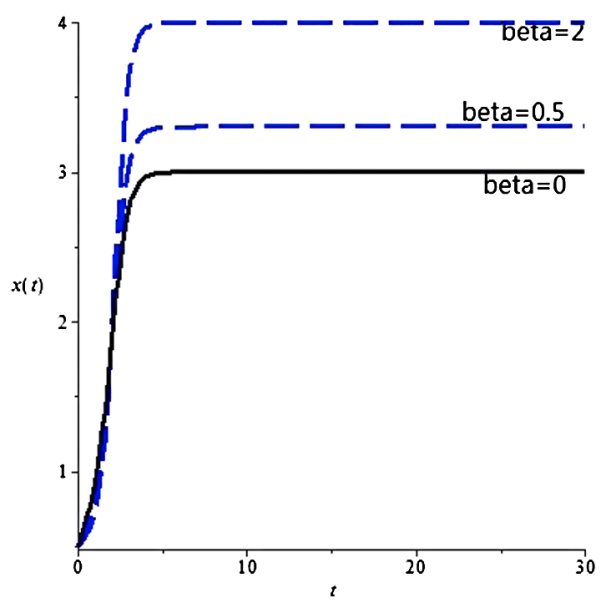




\title{
5 Discussion
}

Many scholars incorporated the Allee effect to the ecosystem and considered the dynamic behaviors of the system, see [28-37]. Some of them [29, 36, 37] focused on the stability property of the positive equilibrium. Çelik and Duman [29] showed that Allee effects have a stabilizing role in the discrete-time predator-prey model, while Merdan [36] showed that the continuous predator-prey system subject to an Allee effect takes a much longer time to reach its stable steady-state solution. Such a phenomenon also was observed in the commensalism model [37]. It came to our attention that with increasing Allee effect, the density of the predator and prey species both decrease [36], and the density of the second species has no change for the commensalism model [37]. In this paper, we showed that the density of the first species is the increasing function of the Allee effect. Such a phenomenon is observed for the first time. Note that with increasing final density, the chance for the extinction of the species will be reduced. It seems that the cooperation between the species plays a crucial role in the persistence property of the endangered species. Also, the more endangered species could have more benefit from cooperation with other species.

\begin{abstract}
Acknowledgements
The author is grateful to the anonymous referees for their excellent suggestions, which greatly improved the presentation of the paper. The research was supported by the National Natural Science Foundation of China under Grant (11601085) and the Natural Science Foundation of Fujian Province (2017J01400).
\end{abstract}

\section{Competing interests}

The authors declare that there is no conflict of interests.

\section{Authors' contributions}

All authors contributed equally to the writing of this paper. All authors read and approved the final manuscript.

\section{Publisher's Note}

Springer Nature remains neutral with regard to jurisdictional claims in published maps and institutional affiliations.

Received: 1 April 2018 Accepted: 9 May 2018 Published online: 22 May 2018

\section{References}

1. Yang, K., Miao, Z.S., Chen, F.D., Xie, X.D.: Influence of single feedback control variable on an autonomous Holling-II type cooperative system. J. Math. Anal. Appl. 435(1), 874-888 (2016)

2. Chen, F.D., Xie, X.D., Chen, X.F.: Dynamic behaviors of a stage-structured cooperation model. Commun. Math. Biol. Neurosci. 2015, Article ID 4 (2015)

3. Yang, K., Xie, X.D., Chen, F.D.: Global stability of a discrete mutualism model. Abstr. Appl. Anal. 2014, Article ID 709124 (2014)

4. Chen, L.J., Xie, X.D.: Feedback control variables have no influence on the permanence of a discrete N-species cooperation system. Discrete Dyn. Nat. Soc. 2009, Article ID 306425 (2009)

5. Yang, L.Y., Xie, X.D., Chen, F.D.: Dynamic behaviors of a discrete periodic predator-prey-mutualist system. Discrete Dyn. Nat. Soc. 2015, Article ID 247269 (2015)

6. Chen, F.D., Yang, J.H., Chen, L.J., Xie, X.D.: On a mutualism model with feedback controls. Appl. Math. Comput. 214, 581-587 (2009)

7. Chen, L.J., Chen, L.J., Li, Z.: Permanence of a delayed discrete mutualism model with feedback controls. Math. Comput. Model. 50, 1083-1089 (2009)

8. Han, R.Y., Chen, F.D., et al.: Global stability of May cooperative system with feedback controls. Adv. Differ. Equ. 2015, Article ID 360 (2015)

9. Xie, X.D., Chen, F.D., Xue, Y.L.: Note on the stability property of a cooperative system incorporating harvesting. Discrete Dyn. Nat. Soc. 2014, Article ID 327823 (2014)

10. Xie, X.D., Chen, F.D., Yang, K., Xue, Y.L.: Global attractivity of an integrodifferential model of mutualism. Abstr. Appl. Anal. 2014, Article ID 928726 (2014)

11. Chen, F.D., Wu, H.L., Xie, X.D.: Global attractivity of a discrete cooperative system incorporating harvesting. Adv. Differ. Equ. 2016, 268 (2016)

12. Chen, F.D., Xie, X.D.: Study on the Dynamic Behaviors of Cooperation Population Modeling. Science Press, Beijing (2014)

13. Yang, W.S., Li, X.P.: Permanence of a discrete nonlinear N-species cooperation system with time delays and feedback controls. Appl. Math. Comput. 218(7), 3581-3586 (2011) 
14. Wu, R.X., Li, L.: Dynamic behaviors of a commensal symbiosis model with ratio-dependent functional response and one party can not survive independently. J. Math. Comput. Sci. 16, 495-506 (2016)

15. Lin, Q.F: Dynamic behaviors of a commensal symbiosis model with non-monotonic functional response and non-selective harvesting in a partial closure. Commun. Math. Biol. Neurosci. 2018, Article ID 4 (2018)

16. Wu, R.X., Li, L., Zhou, X.Y.: A commensal symbiosis model with Holling type functional response. J. Math. Comput. Sci. 16, 364-371 (2016)

17. Li, T.T., Chen, F.D., Chen, J.H., Lin, Q.X.: Stability of a stage-structured plant-pollinator mutualism model with the Beddington-Deangelis functional response. J. Nonlinear Funct. Anal. 2017, Article ID 50 (2017). https://doi.org/10.23952/jnfa.2017.50

18. Li, T.T., Lin, Q.X., Chen, J.H.: Positive periodic solution of a discrete commensal symbiosis model with Holling II functional response. Commun. Math. Biol. Neurosci. 2016, Article ID 22 (2016)

19. Wang, D.H.: Dynamic behaviors of an obligate Gilpin-Ayala system. Adv. Differ. Equ. 2016, Article ID 270 (2016). https://doi.org/10.1186/s13662-016-0965-5

20. Han, R.Y., Chen, F.D.: Global stability of a commensal symbiosis model with feedback controls. Commun. Math. Biol. Neurosci. 2015, Article ID 15 (2015)

21. Xie, X.D., Miao, Z.S., Xue, Y.L.: Positive periodic solution of a discrete Lotka-Volterra commensal symbiosis model. Commun. Math. Biol. Neurosci. 2015, Article ID 2 (2015)

22. Xue, Y.L., Xie, X.D., Chen, F.D., Han, R.Y.: Almost periodic solution of a discrete commensalism system. Discrete Dyn. Nat. Soc. 2015, Article ID 295483 (2015)

23. Miao, Z.S., Xie, X.D., Pu, L.Q.: Dynamic behaviors of a periodic Lotka-Volterra commensal symbiosis model with impulsive. Commun. Math. Biol. Neurosci. 2015, Article ID 3 (2015)

24. Chen, J.H., Wu, R.X.: A commensal symbiosis model with non-monotonic functional response. Commun. Math. Biol. Neurosci. 2017, Article ID 5 (2017)

25. Chen, B.G.: Dynamic behaviors of a non-selective harvesting Lotka-Volterra amensalism model incorporating partial closure for the populations. Adv. Differ. Equ. 2018, Article ID 111 (2018). https://doi.org/10.1186/s13662-018-1555-5

26. Han, R.Y., Xie, X.D., Chen, F.D.: Permanence and global attractivity of a discrete pollination mutualism in plant-pollinator system with feedback controls. Adv. Differ. Equ. 2016, 199 (2016)

27. Zhou, Y.C., Jin, Z., Qin, J.L.: Ordinary Differential Equation and Its Application. Science Press, Beijing (2003)

28. Manna, D., Maiti, A., Samanta, G.P.: A Michaelis-Menten type food chain model with strong Allee effect on the prey Appl. Math. Comput. 311, 390-409 (2017)

29. Çelik, C., Duman, O.: Allee effect in a discrete-time predator-prey system. Chaos Solitons Fractals 90, 1952-1956 (2009)

30. Eduardo, G., Alejandro, R.P., Betsabé, G.Y: Multiple limit cycles in a Leslie-Gower-type predator-prey model considering weak Allee effect on prey. Nonlinear Anal., Model. Control 22(3), 347-365 (2017). https://doi.org/10.15388/NA.2017.3.5

31. Gurubilli, K.K., Srinivasu, P.N.D., Banerjee, M.: Global dynamics of a prey-predator model with Allee effect and additional food for the predators. Int. J. Dyn. Control 5(13), 1-14 (2016)

32. Kang, Y., Yakubu, A.A.: Weak Allee effects and species coexistence. Nonlinear Anal., Real World Appl. 12, 3329-3345 (2011)

33. Sasmal, S.K., Bhowmick, A.R., Khaled, K.A., Bhattacharya, S., Chattopadhyay, J.: Interplay of functional responses and weak Allee effect on pest control via viral infection or natural predator: an eco-epidemiological study. Differ. Equ. Dyn. Syst. 24(1), 21-50 (2015)

34. Kang, Y., Sasmal, S.K., Bhowmick, A.R., Chattopadhyay, J.: A host-parasitoid system with predation-driven component Allee effects in host population. J. Biol. Dyn. 9, 213-232 (2015)

35. Sasmal, S.K., Chattopadhyay, J.: An eco-epidemiological system with infected prey and predator subject to the weak Allee effect. Math. Biosci. 246, 260-271 (2013)

36. Merdan, H.: Stability analysis of a Lotka-Volterra type predator-prey system involving Allee effects. ANZIAM J. 52, 139-145 (2010)

37. Wu, R.X., Li, L., Lin, Q.F:: A Holling type commensal symbiosis model involving Allee effect. Commun. Math. Biol. Neurosci. 2018, Article ID 6 (2018)

38. Zhang, Z.F., Ding, T.R., Huang, W.Z., Dong, Z.X.: Qualitative Theory of Differential Equation. Science Press, Beijing (1992) (in Chinese)

\section{Submit your manuscript to a SpringerOpen ${ }^{\circ}$ journal and benefit from:}

- Convenient online submission

- Rigorous peer review

- Open access: articles freely available online

- High visibility within the field

- Retaining the copyright to your article

Submit your next manuscript at $\gg$ springeropen.com 